\title{
Estramustine/Etoposide/Paclitaxel Regimen
}

National Cancer Institute

\section{Source}

National Cancer Institute. Estramustine/Etoposide/Paclitaxel Regimen. NCI Thesaurus.

Code C11299.

A chemotherapy regimen consisting of estramustine, etoposide, and paclitaxel that may be used in the treatment of hormone-refractory prostate cancer. 